\title{
Monitoramento Participativo de Moradores de Assentamentos Precários na Gestão de Riscos de Escorregamentos: Estudo de caso desenvolvido na Comunidade Vila Nova Esperança ${ }^{1}$
}

\section{Participative Monitoring of Residentes of Precarious Settlements in the Management of Sludge Risks: Case Study developed in Comunity Vila Nova Esperança}

\author{
Viadana, Tazio'; Abiko, Alex ${ }^{2}$ \\ 1 Escola Politécnica - Universidade de São Paulo, Brasil, tazio.viadana@usp.br \\ 2 Escola Politécnica - Universidade de São Paulo, alex.abiko@usp.br
}

\begin{abstract}
RESUMO
Os desastres naturais nas últimas décadas vêm se tornando cada vez mais frequentes, grande parte em decorrência das mudanças climáticas. Uma das maneiras para evitar os desastres de escorregamento de taludes é realizar o monitoramento contínuo das áreas de risco. Devido ao tamanho do município de São Paulo e sua complexidade quanto aos riscos, as instituições públicas não conseguem atender à demanda da gestão de riscos do município. Assim, uma alternativa é realizar medidas preventivas de gestão de riscos, mais simples de ser implementada e menos onerosa do que medidas de resposta. Isso envolveria a participação da população residente em assentamentos precários, em geral desprovida de infraestrutura e serviços públicos, e consequentemente mais vulneráveis aos riscos. Este estudo de caso relata a experiência do monitoramento participativo, etapa do programa Upscaling Resilience aplicado entre comunidades da América Latina, desenvolvido pelas instituições: Heriot-Watt University, University of Edinburgh, Universidad Nacional Colômbia (em Medellín) e a Universidade de São Paulo e também analisar a viabilidade de replicação do monitoramento participativo em áreas de riscos de escorregamento em outras comunidades brasileiras que apresentam áreas de risco de escorregamento.
\end{abstract}

Palavras-chave: Monitoramento, Riscos, Assentamentos Precários.

\begin{abstract}
Natural disasters in recent decades have become increasingly frequent, largely as a result of climate change. One of the ways to avoid slope disasters is to conduct continuous monitoring of risk areas. Due to the size of the municipality of São Paulo and its complexity regarding risks, public institutions cannot meet all the demand of the municipality's risk management. In this way, an alternative is to carry out preventive risk management measures, simpler to implement and less costly than response measures. To do this it would be important to have the participation of the population living in precarious settlements, generally lacking in infrastructure and public services, and consequently more vulnerable to risks. Thus, this study case intends to report on the experience of participatory monitoring, a phase of the Upscaling

${ }^{1}$ VIADANA, Tazio; ABIKO, Alex. Monitoramento participativo de moradores de assentamentos precários na gestão de riscos de escorregamentos: estudo de caso desenvolvido na Vila Nova Esperança. In: II SIMPÓSIO NACIONAL DE GESTÃO E ENGENHARIA URBANA: SINGEURB, 2019, São Paulo. Anais... Porto Alegre: ANTAC, 2019.
\end{abstract}


Resilience program applied among Latin American communities developed by the institutions: Heriot-Watt University, University of Edinburgh, Universidad Nacional Colombia (in Medellín) and the University of São Paulo and also to analyze the feasibility of replication participatory monitoring in landslide risk areas in other Brazilian communities that present areas of risk of landslide.

Keywords: Monitoring, Risk, Precarious settlements.

\section{INTRODUÇÃO}

As mudanças climáticas nas últimas décadas têm ocasionado eventos extremos, os quais muitas vezes resultam em desastres naturais, conforme indicado no gráfico 1. Segundo Eckstein et al (2018), autores do relatório de Índice de Risco Climático, desenvolvido pela Germanwatch para a Conferência das Nações Unidas sobre Mudanças Climáticas de 2018, avalia a vulnerabilidade de 168 países impactados por eventos climáticos extremos no período de 1998 a 2017, onde mais de 11.500 eventos climáticos extremos foram registrados, resultando em mais de 526.000 perdas humanas e um prejuízo de aproximadamente US $\$ 3,47$ trilhões decorrente de perdas e danos a estes eventos. O Brasil ocupa a $79^{a}$ posição, mais de 145 mil pessoas morreram, e os prejuízos por perdas e danos foram superiores a US $\$ 1,71$ bilhão.

O relatório concluiu que oito em cada dez países afetados por catástrofes climáticas são subdesenvolvidos ou em desenvolvimento, grande parte devido a urbanização, intensificada na segunda metade do século XX, isenta de planejamento e políticas públicas de desenvolvimento efetivas, seriam fatores que contribuem para a baixa resiliência a eventos climáticos extremos, especialmente nas parcelas mais vulneráveis destes países (UN-HABITAT, 2011).

Gráfico 1 - Número de eventos causadores de desastres entre 1980-2016

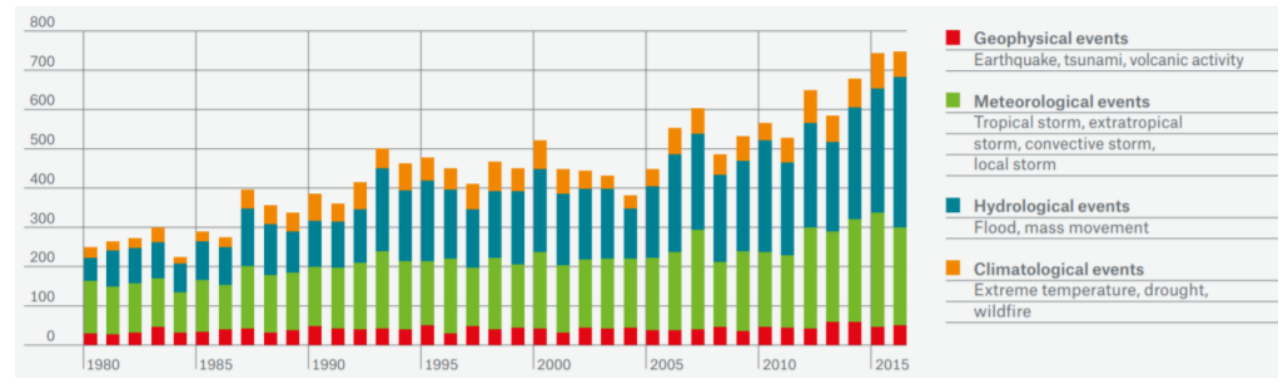

Fonte: Geo Risks Research - NatCatSERVICE (2016)

Neste contexto foi desenvolvido, em 2017, entre as instituições acadêmicas escocesas, University Heriot Watt e University of Edinburgh, e a colombiana, Universidad Nacional de Colombia, o programa Upscaling Resilience, que explorou transferências de estratégias participativas na redução de riscos de escorregamentos em bairros populares na cidade colombiana de Medellín, através da coprodução de serviços básicos entre moradores, e atores dos setores público e privado (SMITH, et. al, 2017).

O programa era composto de 4 etapas: Percepção dos Moradores aos Riscos Expostos, Monitoramento Participativo, Mitigação Comunitária dos Riscos de Deslizamentos e "Concertação", diálogos e acordos entre a comunidade e as instituições públicas ou privadas. Estas etapas contribuíram para o fomento de comunidades resilientes capazes de enfrentar eventos críticos cada vez mais frequentes devido quadro das mudanças climáticas. (SMITH, et al, 2017).

No Brasil, a dificuldade do acesso à cidade formal faz com que uma parcela significativa da sociedade seja marginalizada e ocupe áreas desvalorizadas pelo mercado imobiliário, principalmente devido às restrições impostas para a ocupação legal, seja pelos problemas ambientais existentes ou pelo potencial de risco apresentado (MARICATO, 2015). Grande parte dos assentamentos precários estão localizados em áreas de elevada declividade ou às 
margens de corpos hídricos, propiciando comunidades e gestões urbanas vulneráveis e pouco resilientes. Em 2018, no Brasil, mais de 8 milhões de pessoas moravam em áreas com potencial de riscos de enchentes e deslizamentos, e São Paulo possuía mais de 670 mil moradores em áreas de risco, conforme figura 1 (IBGE, 2018).

Figura 1 - Municípios com os maiores números de pessoas morando em áreas de risco (em milhares)

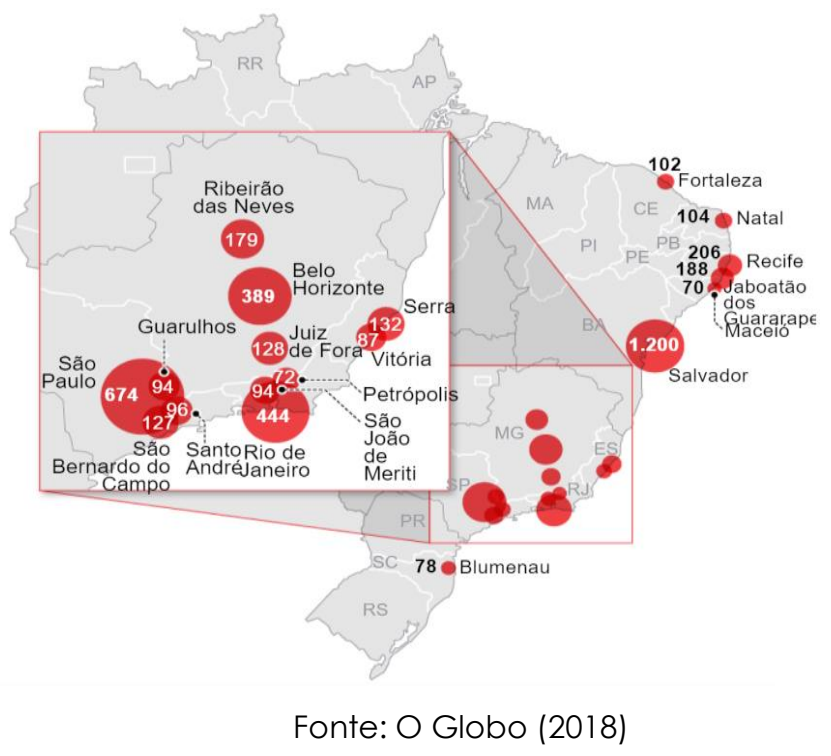

Em 2018, foi realizada a extensão do programa Upscaling Resilience em outras duas comunidades colombianas e em outra comunidade a Vila Nova Esperança.

O objetivo desse estudo de caso é relatar a realização do monitoramento sistemático de áreas de risco de deslizamento em uma comunidade vulnerável, capacitando seus moradores, através da experiência do programa Upscaling Resilience, adaptando sua metodologia utilizada nas comunidades colombianas à realidade brasileira.

\section{METODOLOGIA DO MONITORAMENTO}

A metodologia do monitoramento participativo foi aplicada na Vila Nova Esperança, assentamento informal com aproximadamente 600 famílias, localizado no município de São Paulo, distrito Raposo Tavares, pertencente à subprefeitura do Butantã.

A metodologia adotada consiste em:

- Selecionar em conjunto com os moradores os pontos de monitoramento;

- Capacitar os moradores em como elaborar os registros fotográficos, filmes e observações dos pontos críticos de deslizamentos para uso do pesquisador;

- Motivar o morador a efetuar o registro de forma sistemática, no mínimo uma vez por semana, observando as condições climáticas do dia e prevalecendo essas observações após as chuvas,

- Analisar as fotos e identificar possíveis alterações no território.

\subsection{Seleção dos pontos de monitoramento}

Os pontos localizados nas áreas de risco foram escolhidos após entrevistas com moradores comunidade. Foram realizadas visitas aos locais indicados no mapa de risco elaborado pelo 
IPT2 e incluem os pontos localizados no talude próximo à Rua Progresso, como também os pontos localizados nas vielas para monitoramento de águas pluviais e lançamento de esgoto sobre o talude. Foram definidos 7 pontos de monitoramento, indicados na figura 2.

Figura 2 - Pontos de Monitoramento na Vila Nova Esperança

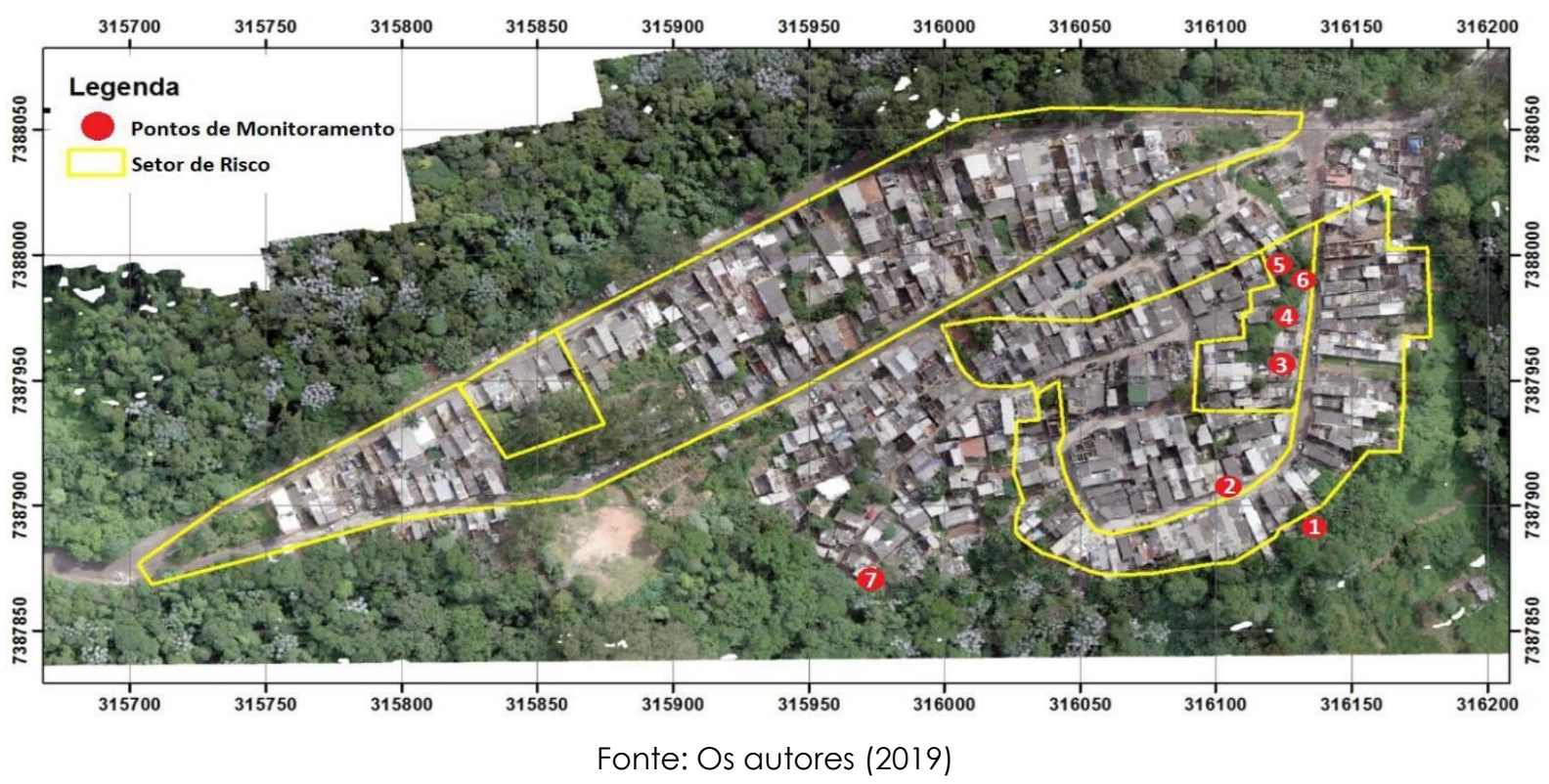

\subsection{Registro fotográfico e de vídeos}

Os moradores, selecionados para o monitoramento, estavam habituados a utilizar recursos de comunicação digital direta com os membros da equipe. Esses moradores foram voluntários em participar e possuíam smartphones com acesso à internet. Os moradores foram treinados para monitorar as áreas críticas, observando e registrando qualquer alteração no comportamento do solo como: inclinações de árvores, muros e postes, surgimento ou aumento de trincas no solo ou nas moradias, desprendimento de solo e a poluição difusa como presença de lixo ou entulho, bem como o lançamento de águas servidas, esgotos e águas pluviais sobre o talude, conforme figura 3.

Figura 3 - Morador da Vila Nova Esperança sendo instruído pelo funcionário do Instituto Geológico.

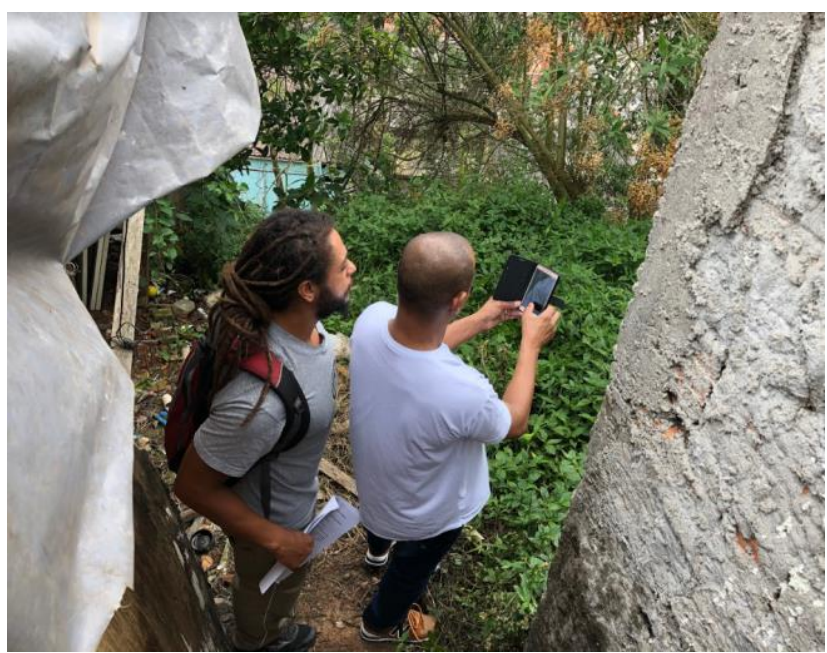

Fonte: Os autores (2018)

2 IPT -Instituto de Pesquisas Tecnológicas, instituto vinculado à Secretaria de Desenvolvimento Econômico do Estado de São Paulo, fundado em 1899 e atua nas áreas de pesquisa, educação e tecnologia, oferecendo apoio tecnológico nos setores públicos e privados. 
Os moradores foram instruídos realizar registros fotográficos, ou gravação de vídeos, de preferência sempre no mesmo ângulo para não haver distorções nas imagens obtidas para efeito de comparação.

\subsection{Envio das fotos e vídeos}

O aplicativo escolhido para a comunicação entre o pesquisador e os moradores foi o Whatsapp, aplicativo livre e de fácil utilização. As fotos eram enviadas ao pesquisador do projeto e arquivadas em pastas específicas para o ponto de monitoramento devidamente identificado.

Inicialmente, o pesquisador optou por comunicar-se individualmente através do aplicativo, sendo necessário lembrar-lhes toda a semana da importância de realizar o registro fotográfico das áreas de risco. Posteriormente, foi criado um grupo no Whatsapp que tinha como objetivo discutir alternativas para a mitigação dos riscos de deslizamento, alguns membros deste grupo passaram a realizar os registros fotográficos das áreas de risco, sem que o pesquisador solicitasse.

Os próprios moradores, do grupo de mitigação, passaram a solicitar e a lembrar os demais membros do grupo a realizar o registro fotográfico das áreas de risco, sem a necessidade de um pesquisador para lembrar das tarefas semanais. Dessa forma, a comunicação entre os moradores através de um grupo de Whatsapp, mostrou-se mais eficiente do que de maneira individual.

\subsection{Análise do material enviado}

Os registros enviados eram analisados semanalmente, de maneira qualitativa, comparando com os registros da semana anterior e verificando alterações significativas para alertar os moradores do local de um aumento no risco de deslizamento, mostrando aos moradores alterações observadas e suas consequências com auxílio dos registros.

\section{RESULTADOS E DISCUSSÕES}

O monitoramento participativo iniciou-se em outubro de 2018, escolhendo preferencialmente moradores cujas residências estavam localizadas próximas dos pontos a serem monitorados e encerrou-se em fevereiro de 2019. O quadro 1 apresenta detalhes sobre os moradoresmonitores.

Quadro 1 - Relação dos Moradores-Monitores da Vila Nova Esperança

\begin{tabular}{|c|c|c|c|c|c|}
\hline Ponto & Monitor & Área onde mora & Início & Fim & Risco monitorado \\
\hline 1 & Morador 1 & $\begin{array}{c}\text { Rua Progresso } \\
\text { área do Bota- } \\
\text { fora }\end{array}$ & $11 / 10 / 18$ & $19 / 10 / 18$ & Talude do bota-fora \\
\hline 2 & Morador 2 & $\begin{array}{c}\text { Rua Progresso } \\
\text { área do bota- } \\
\text { fora }\end{array}$ & $09 / 11 / 18$ & $08 / 03 / 19$ & Viela de drenagem \\
\hline 3 & Morador 3 & Rua Progresso & $11 / 10 / 18$ & $06 / 02 / 19$ & $\begin{array}{c}\text { Talude progresso com } \\
\text { lonas plásticas }\end{array}$ \\
\hline 4 & Morador 4 & Rua Progresso & $27 / 10 / 18$ & $15 / 12 / 18$ & Talude R. Progresso \\
\hline 5 & Morador 5 & Rua Paraíso & $04 / 02 / 19$ & $12 / 03 / 19$ & Talude R. Progresso \\
\hline 6 & Morador 6 & Travessa C & $19 / 10 / 18$ & $08 / 03 / 19$ & $\begin{array}{c}\text { Quintal /Talude R. } \\
\text { Progresso }\end{array}$ \\
\hline 6 & Morador 7 & Travessa C & $04 / 10 / 18$ & - & Talude R. Progresso \\
\hline 7 & Morador 8 & Área da Mata & $16 / 10 / 18$ & $21 / 12 / 18$ & $\begin{array}{c}\text { Escada hidráulica } e \\
\text { Área da mata }\end{array}$ \\
\hline
\end{tabular}

Fonte: Os autores (2019) 


\subsection{Fatores que dificultaram o monitoramento participativo}

Foi necessário considerar a vulnerabilidade dos moradores. Por exemplo, no caso dos moradores 1 e 8 eles residem em áreas de elevada vulnerabilidade, e, portanto, foram incluídos como monitores e instruídos para as observações necessárias e uso do registro fotográfico. Porém, devido às diversas complicações como: parente próximo portador de necessidades especiais, uso de substâncias psicoativas ou por residir em área localizada em novo vetor de expansão da comunidade, esses moradores deixaram de monitorar as áreas.

O grau de risco não foi um fator determinante para convencer o morador monitor em participar ativamente do monitoramento dos pontos demarcados. Moradores que monitoravam áreas de risco alto, eram mais disciplinados e interessados do que os que monitoravam áreas de risco muito alto, reforçando a questão da vulnerabilidade como fator preponderante para o bom desempenho do monitoramento.

Moradores idosos não possuíam habilidade, nem a prática de operar o celular e seus aplicativos, no entanto, moradores jovens, caso dos Moradores 4 e 7, perdiam o interesse durante o monitoramento e não enviavam as fotos, sendo constantemente solicitados pelo pesquisador para a importância do envio das fotos para acionar seus moradores em tempo para prevenir um acidente.

A questão do emprego foi outro fator que exigiu atenção. O morador 3 na época estava desempregado e se comprometeu a tirar fotos, porém, após conseguir um emprego deixou de enviar os materiais, justificou que saia muito cedo e retornava muito tarde para o trabalho e não era possível visualizar os pontos porque ainda era noite.

A insegurança de permanência e medo de serem removidos foram outros fatores que dificultaram 0 início das entrevistas para a análise das áreas risco de escorregamento. Inicialmente os moradores afirmavam que a comunidade não possuía taludes íngremes e com potenciais riscos de escorregamento, com medo de serem removidos do local, por confundirem os pesquisadores com funcionários de instituições públicas que pudessem removê-los.

\subsection{Fatores que colaboraram com o monitoramento participativo}

O tempo de permanência na comunidade, geralmente superior a 5 anos, conferia ao morador uma ideia de posse e pertencimento do local, justificando seu real interesse em participar do monitoramento.

Moradores casados e com filhos possuíam maior interesse no monitoramento. Conforme entrevistas, eles se mostravam preocupados com a segurança da família que permanecia na casa enquanto estava no trabalho.

Tratar o monitoramento de modo coletivo e não individual, criando um grupo comum no Whatsapp para monitorar os riscos tornou-se um instrumento útil, simples e autônomo para os moradores das áreas de risco, fazendo com que relatassem possíveis alterações online e interagissem de forma mais dinâmica.

Antigos moradores participantes do programa NUDEC - Núcleo Comunitário de Defesa Civil, promovido pela Defesa Civil, fez com que esses moradores tivessem interesse em monitorar os riscos.

A participação do pesquisador em atividades que envolvessem a comunidade, como visitas constantes à comunidade e em mutirões, fizeram com que os moradores adquirissem uma confiança no pesquisador, mostrando os riscos não apenas de deslizamento, mas outros problemas decorrentes da precariedade do local.

\section{CONCLUSÕES}

O monitoramento das áreas de risco da comunidade Vila Nova Esperança realizado pelos próprios moradores mostrou-se eficiente principalmente por despertar 0 interesse e a 
conscientização sobre os riscos de deslizamento a que estão sujeitos e como obter respostas mais resilientes a esses eventos.

O monitoramento participativo mostrou-se propício a ser reproduzido em outras comunidades que possuem áreas de risco de escorregamento.

A análise sistemática das fotos e sua interpretação leva essa população a dialogar com o poder público sob forma de coparticipação frente ao problema a ser enfrentado e fornece subsídios para a intervenções que possam ser realizadas pela própria comunidade ou pelo poder público.

\section{AGRADECIMENTOS}

Para a realização deste artigo agradecemos primeiramente aos moradores da Vila Nova Esperança por receberem e aceitarem o desenvolvimento desse projeto.

Agradecemos aos pesquisadores do Instituto de Pesquisas Tecnológicas e ao Instituto Geológico pelo auxílio e acompanhamento do desenvolvimento do programa "Coprodução na Gestão de Riscos de Escorregamentos em Assentamentos Precários"

\section{REFERÊNCIAS}

BANCO MUNDIAL (1999-2001). Upgrading Urban Comunities a Resource for Practitioners. Disponível em <http://web.mit.edu/urbanupgrading/index.html> acesso em abr de 2019

BRASIL, IBGE - Instituto Brasileiro de Geografia e Estatística. População em Áreas de Risco no Brasil, Rio de Janeiro. 2018. Disponível em <https://www.ibge.gov.br/geociencias/organizacao-do-territorio/tipologias-doterritorio/21538-populacao-em-areas-de-risco-no-brasil.html> acesso em abr de 2019

Secretaria de Planejamento e Investimentos Estratégicos, SIGPLAN 1029 / PPA 20082011 Respostas ao Desastres e Reconstrução, disponível em <http://www.planejamento.gov.br/assuntos/planeja/plano-plurianual/ppas-anteriores> acesso em abr de 2019

ECKSTEIN, D., HUTFILS M. e WINGES M. Global Climate Risk Index 2019. Germanwatch, dez de 2018. Disponível em < https://www.germanwatch.org/en/cri> acesso em abr 2019

MARICATO, E. Para entender a Crise Urbana, $1^{a}$ Ed. Expressão Popular, 2015, 112p.

SMITH, H., Coupe F., Medero, G.M. CABALLERO, H. A. et al, ¿Resiliencia o Resistencia? Mitigación Negociada de los Riesgos De Deslizamiento en Asentamientos Informales en Medellín. NERC Science of the Environment (2017) disponível em < http://www.medellin-urbaninnovation.eca.ed.ac.uk/wp-content/uploads/2018/04/Informe_Sintesis.pdf > acesso em abr de 2019

UNITED NATIONS HUMAN SETTLEMENTS PROGRAMME [UN-HABITAT]. Cities and climate change: policy directions. Global report on human settlements, 2011. Disponível em: <http://www.unhabitat.org/downloads/docs/GRHS2011/GRHS.2011.Abridged.English.pdf>. Acessado: jun de 2019 